\title{
Asymmetric Suzuki-Miyaura Coupling in Water Using a Chiral Polymeric Pd Catalyst
}<smiles>[X]c1c([2H])ccc2ccccc12</smiles>

$\mathrm{R}^{1}=\mathrm{Me}, \mathrm{OMe}, \mathrm{OEt}, \mathrm{CO}_{2} \mathrm{Me}, \mathrm{P}(\mathrm{O})(\mathrm{OEt})_{2}$ $\mathrm{X}=\mathrm{Cl}, \mathrm{Br}, \mathrm{I}$<smiles>[R]c1ccc(Br)c(P)c1</smiles><smiles>Cc1ccc2ccccc2c1[OH2+]</smiles>

\section{$\mathrm{Pd}(\mathrm{OAc})(10 \mathrm{~mol} \% \mathrm{Pd})$ PS-PEG-L* $(\mathrm{Pd} / \mathrm{P}=1: 1)$ \\ $n-\mathrm{Bu}_{4} \mathrm{NF}, \mathrm{H}_{2} \mathrm{O}, 80^{\circ} \mathrm{C}, 24 \mathrm{~h}$} $\mathrm{R}^{2}=\mathrm{Me}, \mathrm{OMe}, \mathrm{OEt}$ 10 examples recycling experiments $\mathrm{R}^{1}=\mathrm{Me}, \mathrm{R}^{2}=\mathrm{OMe}, \mathrm{X}=\mathrm{Br}$ average of four recycling runs: $86 \%$ yield, $88 \%$ ee $(S)$

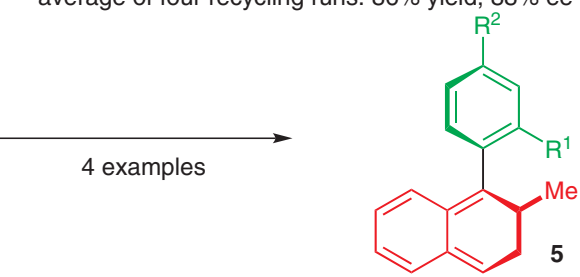

96-89\% yield, $94-92 \%$ ee

$\mathrm{R}^{1}=\mathrm{Me}, \mathrm{R}^{2}=\mathrm{H} ; \mathrm{R}^{1}=\mathrm{Me}, \mathrm{R}^{2}=\mathrm{CN}$

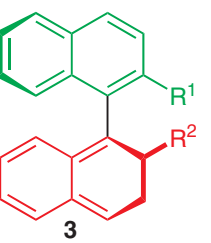

Significance: Asymmetric Suzuki-Miyaura coupling in water with a novel recyclable palladium complex of a polymer-supported chiral imidazoindole phosphine ligand was described. Thus, PS-PEG-supported imidazoindole dicyclohexylphosphine (PS-PEG-L*, 7) was prepared from PS-PEG-NH $\mathrm{H}_{2}$ and compound $\mathbf{6}$. The reaction of 2-methyl-1-iodonaphthalene with 2-methylnaphthyl boronic acid was catalyzed by the amphiphilic polymeric PS-PEG-L*-Pd complex to give 2,2'dimethyl-1,1'-binaphthyl in 95\% yield with $94 \%$ ee (S). The catalyst PS-PEG-L*-Pd was recovered readily and reused four times with little loss of its catalytic activity and stereoselectivity.
Comment: The highly stereoselective asymmetric Suzuki-Miyaura coupling affording axially chiral biaryls is an eagerly awaited reaction to stand by itself. Heterogeneous and aqueous switching of the asymmetric coupling were realized for the first time via anchoring the catalyst onto an amphiphilic polymer resin beads. Thus, this communication should become a focus of attention from both viewpoints of asymmetric catalysis and polymersupported synthesis. Coupling of the naphthyl chloride also took place under similar conditions with excellent enantiomeric selectivity. 